\title{
The Investigation of Adsorption Behaviors of Nine Ionic Liquid-Immobilized Silicas on Two Phenols in Water and Soil Samples
}

\author{
Minglei TIAN *, Xuemin YAN, Wei XIAO, Liangwen LIN \\ College of Chemistry and Environmental Engineering, Yangtze University, Jingzhou, 434023, China \\ crossref http://dx.doi.org/10.5755/j01.ms.26.1.20031
}

Received 25 January 2018; accepted 21 September 2018

\begin{abstract}
An experimental study on adsorption of phenol and o-cresol using ionic liquid-immobilized silica contained different functional groups was carried out. The effects of various operating parameters such as type of ionic liquid group, different adsorption time and ambient temperatures, different solvents in solid phase extraction (SPE) process and several aqueous ion solutions on adsorption of two phenols had been experimentally investigated. It was found that amino ionic liquid-immobilized silica had the highest adsorption efficiency and stability. The optimized adsorption conditions were 15 min under $35^{\circ} \mathrm{C}$. In SPE, the acidity solution such as ethanol- $\mathrm{HCl}\left(0.1 \%\right.$ vol.) and $\mathrm{NaH}_{2} \mathrm{PO}_{4} \mathrm{could}$ reduce the adsorption efficiency of sorbents. Finally, the sorbent was applied to determining two phenols in real samples and relative standard deviation (RSD) less than $6.14 \%$ showed the high precision.

Keywords: ionic liquid, immobilized silica, phenols, water, soil.
\end{abstract}

\section{INTRODUCTION}

Along with the development of the industry, pollution of water and soil from inorganic and organic compounds has increased rapidly in recent decades. Large amount of aqueous pollutions has toxicological effects in humans and animals [1]. Phenols are one of the major organic compounds used in several chemical manufacturing processes, also they are used as an antiseptic or added in disinfectant [2]. Phenols are toxic and had a carcinogenic effect, therefore of considerable health concern to human and aquatic lives when released to the environment. The concentrations of phenol in industrial effluents are normally in a range of $2.8-6800.0 \mathrm{ppm}$ which is much higher than the LD50 for aquatic lives [3]. For these reasons, removing phenols is one of the main aims in water and soil treatment.

Various treatment methods like ozonation, distillation, liquid extraction, pervaporation, membrane extraction, biological based processes and different kinds of electrochemical methods were currently practiced for phenolic compounds removal [4-8]. Kallel et al. used iron oxidation to remove phenolic compounds with $\mathrm{pH}$ in the range between 2 and 4, the maximum value removal is at the level of $92 \%$ [4]. Chedeville et al. used ozonation to treat wastewater under $\mathrm{pH}=5$, after process the abatement of phenolic compounds reached $80 \%$ [5]. Parida and Pradhan removed phenolic compounds by adsorption onto manganese nodule leached residue, under $4 \mathrm{~h}$ equilibrium time $28.5 \mathrm{mg} / \mathrm{g}$ of phenol can be adsorbed at $\mathrm{pH}=3$ [6]. Yavuz et al. treated wastewater by electrochemical oxidation. $99.5 \%$ phenol was removed at $40 \mathrm{~min}$ of electrolysis with density of $5 \mathrm{~mA} / \mathrm{cm}^{2}$ [8].

Although these techniques provide accurate results, they have several disadvantages, such as the requirement of expensive apparatus, complicated operation with high costs, and the requirement of well-controlled experimental conditions. In the case, the most favourable technique is adsorption using sorbents.

Ionic liquids (ILs), a green reaction media with excellent chemical properties, are employed as a modifier. ILs are receiving a lot of attention in the fields of analytical chemistry, sample preparation, organic synthesis, liquidphase extraction, and chromatographic separations [9-13]. The characteristics, such as hydrophobicity, miscibility with several inorganic/organic solvents, $\pi-\pi$ interactions between analyte and functional groups of the ionic liquids, are widely applied [14]. Some researches were already published using IL or IL based materials to extract phenols from water solutions [15-19]. Balasubramanian and Venkatesan removed phenolic compounds using IL in tributyl phosphate solution, the result was observed that $0.02 \%(\mathrm{v} / \mathrm{v})$ of IL [BMIM] $\left[\mathrm{PF}_{6}\right]$ can remove $99.5 \%$ of phenols at $\mathrm{pH}=6.5$ [17]. Raoov et al. synthesized a cyclodextrin-ionic liquid polymer, and the sorbent adsorbed $29.6 \mathrm{mg} / \mathrm{g}$ of phenolic compound under $\mathrm{pH}=6$ and $180.0 \mathrm{~min}$ [18].

Solid-phase extraction (SPE) is one of the most convenient and high-performance separation technologies that can help minimize the use of organic solvents, which are regulated as priority pollutants. Li et al. [20] and Wang et al. [21] successfully applied SPE in separation of harmful compounds. So in this research, adsorption of ocresol and phenol from aqueous solutions using ILimmobilized silica contained different groups was evaluated using SPE method. IL groups were based on imidazole which contained different carbon chains and side groups. In SPE process, aqueous ions solution and several organic solvents were used in washing and elution steps. Also the effect of adsorption time and ambient temperature were investigated.

\footnotetext{
${ }^{*}$ Corresponding author. Tel.: +86-716-8060933

E-mail address: tianm086@126.com (M. Tian)
} 


\section{EXPERIMENTAL DETAILS}

\subsection{Chemicals}

Silica $\quad(40 \mu \mathrm{m}), \quad$ (3-chloropropyl)-trimethoxysilan, imidazole, 1-methylimidazole, 1-ethylimidazole, 1-butylimidazole, 1-hexylimidazole, 1,2-dichloroethane, 1,4-dichlorobutane, 1,6-dichlorohexane, 2-chloroethylamine, phenol and $o$-cresol were purchased from Aladdin Inc. (Shanghai, China) and all grades of purity were higher than $98 \%$. Organic solvents such as ethanol, toluene, triethylamine et al. were supported by Beilian Company (Tianjing, China) and purities were higher than $99.7 \%$. Water, all organic solvents and samples should be filtered before use.

\subsection{Preparation of IL-immobilized silica}

Silica was first washed by distilled water and ethanol, and activated in a vacuum oven under $120{ }^{\circ} \mathrm{C}$ for $4 \mathrm{~h}$. Then two groups of activated silica were synthesized by following steps shown in Fig. 1.

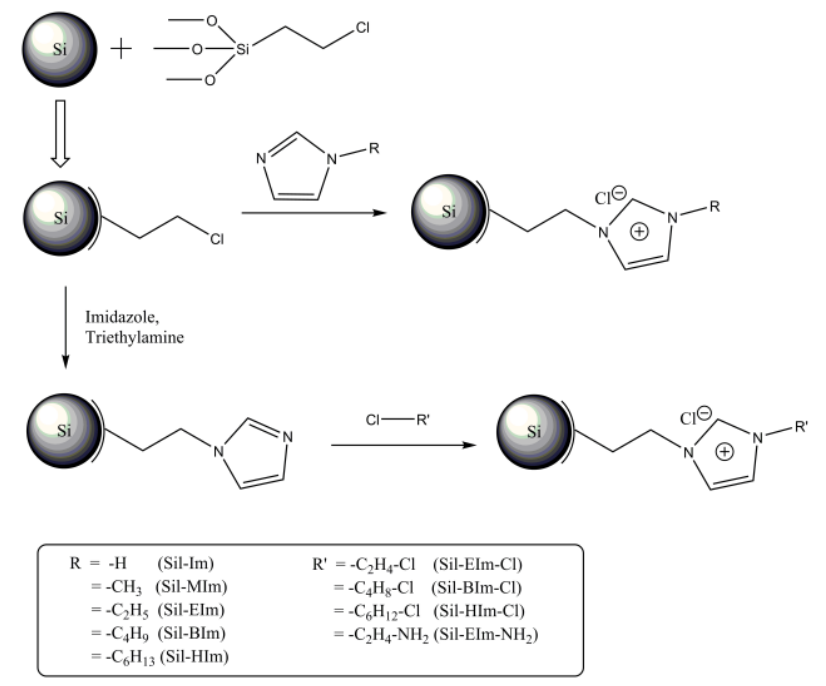

Fig. 1. Synthesis process of nine IL-immobilized silicas

For the first group, $25.0 \mathrm{~g}$ of silica, $25.0 \mathrm{~mL}$ of (3-chloropropyl)trimethoxysilane and $100.0 \mathrm{~mL}$ of toluene were well mixed in a flask, and the mixture was heated to $100{ }^{\circ} \mathrm{C}$ for $12 \mathrm{~h}$. When the powder was washed by ethanol and fully dried, chloropropyl silica (Sil-Cl) was obtained. Then five flasks contained $5.0 \mathrm{~g}$ of Sil- $\mathrm{Cl}$ and $50.0 \mathrm{~mL}$ of toluene were prepared, $5.0 \mathrm{~g}$ of imidazole, 1-methylimidazole, 1-ethylimidazole, 1-butylimidazole and 1-hexylimidazole were added into flask respectively. After all flasks were heated and refluxed for $12 \mathrm{~h}$, IL-immobilized silicas such as imidazole chloride-silica (Sil-Im), 1-methylimidazole chloride-silica (Sil-MIm), 1-ethylimidazole chloride-silica (Sil-EIm), 1-butylimidazole chloride-silica (Sil-BIm) and 1-hexylimidazole chloride-silica (Sil-HIm) were obtained. For the second group, $25.0 \mathrm{~g}$ of Sil-Cl was prepared as well and it mixed with $28.0 \mathrm{~g}$ of imidazole $(15.0 \mathrm{~g}$ of triethylamine as a catalyst) in $200.0 \mathrm{~mL}$ of toluene. After the mixture was heated to $100{ }^{\circ} \mathrm{C}$ for $12 \mathrm{~h}$, the obtained imidazole-silica was dried at $80{ }^{\circ} \mathrm{C}$ for overnight. Then four flasks contained $5.0 \mathrm{~g}$ of imidazoel-silica and $50.0 \mathrm{~mL}$ of toluene were prepared, $5.0 \mathrm{~g}$ of 1,2-dichloroethane, 1,4-dichlorobutane, 1,6-dichlorohexane and 2-chloroethylamine were added into flasks respectively. After all flasks were heated and refluxed for $12 \mathrm{~h}$, ILimmobilized silicas such as Sil-EIm-Cl, Sil-BIm-Cl, Sil$\mathrm{HIm}-\mathrm{Cl}$ and Sil-EIm-NH $\mathrm{N}_{2}$ can be obtained. All ILimmobilized silicas were washed by diluted water, ethanol and acetone, and fully dried for further experiments. The characteristics of all obtained silicas were analyzed by FTIR (Nicolet 6700, Thermo Fisher, Waltham, USA) in the range of $400-4000 \mathrm{~cm}^{-1}$ with a scan rate of $20 \mathrm{scans} / \mathrm{min}$ and TGA (Labsys evo, Setaram, Caluire, France) with a heating rate of $10^{\circ} \mathrm{C} / \mathrm{min}$ under $\mathrm{N}_{2}$.

\subsection{Preparation of silica-physically adsorbed-ILs}

Three $100 \mathrm{~mL}$ flasks contained $10.0 \mathrm{~g}$ of 1-methylimidazole were prepared and $17.0 \mathrm{~g}$ of 1,2-dichloroethane, $23.0 \mathrm{~g}$ of 1,4-dichlorobutane and $28.0 \mathrm{~g}$ of 1,6-dichlorohexane were added into each flask. Three mixtures were stirred and heated until refluxing for $24 \mathrm{~h}$. Then the mixtures were evaporated to remove excess alkyl halides and washed by diethyl ether. After fully drying in oven, three ionic liquid 1-ethyl-3methylimidazolium chloride ([EMIm]Cl), 1-butyl-3methylimidazolium chloride $([\mathrm{BMIm}] \mathrm{Cl})$ and 1-hexyl-3methylimidazolium chloride $([\mathrm{HMIm}] \mathrm{Cl})$ were obtained. Each obtained IL was added into $1.0 \mathrm{~g}$ of actived silica and the adsorption equilibrium would be achieved completely in $2 \mathrm{~h}$. Then three silica-physically adsorbed-IL sorbents $\mathrm{Sil} /[\mathrm{EMIm}] \mathrm{Cl}, \quad \mathrm{Sil} /[\mathrm{BMIm}] \mathrm{Cl}$ and $\mathrm{Sil} /[\mathrm{HMIm}] \mathrm{Cl}$ were prepared.

\subsection{Adsorption efficiency of sorbents with SPE}

$0.3 \mathrm{~g}$ of each IL-immobilized silica was packed into nine SPE cartridges $(\varnothing 0.9 \mathrm{~cm}$, Alltech, Deerfield, IL, USA) and two groups of such cartridges were prepared. Then water, methanol and acetone were alternately added into cartridges to clean the materials. After pretreatment, loading, washing, elution and cleaning steps with different solvents were orderly applied into SPE process. In loading step, $0.1 \mathrm{~mL}$ of $0.01 \mathrm{mg} / \mathrm{mL}$ of $o$-cresol and phenol solutions were dropwised into each cartridge group. After the solutions were well dispersed into sorbents, the cartridges were placed for $30 \mathrm{~min}$ until adsorption equilibrium obtained. Then in washing step $3.0 \mathrm{~mL}$ of water was dumped into each cartridge according to the amount of sorbents, after through the materials washing water were collected and analyzed by HPLC. In elution step, several organic solvents with different polarities (methanol, ethanol, acetonitrile, hexane and chloroform) were selected as elution solvent to remove phenols after washing step. Then $3.0 \mathrm{~mL}$ of solvent contained $0.1 \%$ (vol.) $\mathrm{HCl}$ which had higher elution ability was used in cleaning step to remove rest of phenols from materials. Solutions from each process were analyzed by HPLC (LC3000, CXTH, Beijing, China). The chromatographic conditions were: a commercial $\mathrm{C}_{18}$ column $(4.6 \times 250 \mathrm{~mm}$, $5 \mu \mathrm{m}$, RStech Co., Daejeon, Korea) with methanol/water (80:20, v/v) as mobile phase. The flow rate, UV wavelength, and injection volume were $0.5 \mathrm{~mL} / \mathrm{min}$, $270 \mathrm{~nm}$ and $20.0 \mu \mathrm{L}$, respectively. 


\subsection{Change of adsorption time and temperature}

$o$-Cresol and phenol had similar adsorption behaviors on sorbents, so $o$-cresol was selected. Firstly, under room temperature $0.3 \mathrm{~g}$ of Sil-EIm- $\mathrm{NH}_{2}$ was mixed with $0.1 \mathrm{~mL}$ of $0.01 \mathrm{mg} / \mathrm{mL} o$-cresol within different adsorption time from $0.3 \mathrm{~min}$ to $30 \mathrm{~min}$. Then same amount of Sil-Im- $\mathrm{NH}_{2}$ and $o$-cresol solution was mixed under increasing temperature from $15{ }^{\circ} \mathrm{C}$ to $70{ }^{\circ} \mathrm{C}$. At different time and temperature points, $3.0 \mathrm{~mL}$ of ethanol- $\mathrm{HCl}(0.1 \%$ vol.) was used to remove unadsorbed $o$-cresol. Each point was repeated 7 times and analyzed by HPLC.

\subsection{Effect of adsorption by several ions}

$0.1 \mathrm{~mol} / \mathrm{L}$ of several salt aqueous solutions such as $\mathrm{NaCl}, \mathrm{KCl}, \mathrm{MgCl}_{2}, \mathrm{AlCl}_{3}, \mathrm{CaCl}_{2}, \mathrm{FeCl}_{3}, \mathrm{Na}_{2} \mathrm{CO}_{3}$, $\mathrm{NaHCO}_{3}, \mathrm{Na}_{2} \mathrm{HPO}_{4}$ and $\mathrm{NaH}_{2} \mathrm{PO}_{4}$ were prepared. In order to evaluate the effect of salt after fully equilibrium, the adsorption and desorption time were increased by adding more volume of solvents. After loading the $1.0 \mathrm{~mL}$ of $0.01 \mathrm{mg} / \mathrm{mL}$ of phenol in SPE cartridges with $3.0 \mathrm{~g}$ of SilIm, Sil-EIm-Cl and Sil-Im- $\mathrm{NH}_{2}$ as sorbents, $10.0 \mathrm{~mL}$ of salts aqueous solutions were used in SPE and amounts of unadsorbed phenol were analyzed.

\subsection{Preparation of real water and soil samples}

Four environmental water samples were obtained from the Yangtze River, a lake, a well and plant effluent. After filtration, $10.0 \mathrm{~mL}$ of four water samples were loaded into SPE cartridges. Three soil samples were taken from different places near a plant and each of them was stirring with $10.0 \mathrm{~mL}$ of pure water for $30 \mathrm{~min}$, then the filtered water layers were also loaded into SPE cartridges with $3.0 \mathrm{~g}$ of sorbents. After loading process, elution and washing processes were followed the previous optimized steps.

\section{RESULTS AND DISCUSSION}

\subsection{Adsorption ability of commercial resins}

First of all, the calibration curves were constructed using the chromatographic peak areas measured at seven increasing concentrations, ranging from $0.001-0.025 \mathrm{mg} / \mathrm{mL}$ for $o$-cresol and $0.005-0.1 \mathrm{mg} / \mathrm{mL}$ for phenol. Good linearity was obtained and the linear correlation equations were $\mathrm{y}=53.491 \mathrm{x}+0.0413$ $\left(\mathrm{R}^{2}=0.997\right)$ for $o$-cresol and $\mathrm{y}=15.463 \mathrm{x}+0.0453$ $\left(\mathrm{R}^{2}=0.999\right)$ for phenol ( $\mathrm{y}$ is peak area and $\mathrm{x}$ is the concentration of phenols in solution).

Normally macro-resin was widely used in waste water treatment with materials adsorption technology. However adsorption efficiencies and stabilities under high temperature were partially unsatisfactory. In order to prejudge the effect of adsorption efficiency between functional group and phenols, commercial silica $(0.1 \mathrm{~g})$, two base properties resins $\left(0.2 \mathrm{~g}\right.$ of each, Amberlite ${ }^{\circledR}$ IRA402 and 717, Dow Chemical Company, Michigan, USA) and one acid property resin (0.2 g, Amberlite ${ }^{\circledR} 732$, Dow Chemical Company, Michigan, USA) were static mixed with $3.0 \mathrm{~mL}$ of $0.05 \mathrm{mg} / \mathrm{mL}$ phenols aqueous solution for $60 \mathrm{~min}$.
After analysis, the adsorption amounts for $o$-cresol were $0.12 \mathrm{mg} / \mathrm{g}$ on silica, $0.23 \mathrm{mg} / \mathrm{g}$ and $0.17 \mathrm{mg} / \mathrm{g}$ on two base properties resins, nothing was adsorbed on acid property resin. For phenol the amounts were $0.076 \mathrm{mg} / \mathrm{g}$, $0.47 \mathrm{mg} / \mathrm{g}, \quad 0.76 \mathrm{mg} / \mathrm{g}$ and $0.00 \mathrm{mg} / \mathrm{g}$ respectively. The results showed that the materials contained base group had much stronger interaction with phenols. Although adsorption efficiency of silica was a little far from base groups, it had large surface area and supplied hydrogen bonds. So in the following researches IL-silicas with/without base group should be investigated.

\subsection{Characterization}

In the FT-IR spectra (Fig. 2), except silica the other nine sorbents showed the appearance of peaks nearby $1572.3 \mathrm{~cm}^{-1}$ which is the finger print region of IL groups. Sil-BIm and Sil-HIm showed a peak at $1481.4 \mathrm{~cm}^{-1}$ which belongs to -C-C- bond. Sil-EIm also showed this peak but quite smaller because of less amount of -C-C-bonds. The vibration range of $-\mathrm{C}-\mathrm{H}$ group in alkanes is $2850.0-3000.0 \mathrm{~cm}^{-1}$ so the peaks at $2942.2 \mathrm{~cm}^{-1}$ belong to the carbon chain [22, 23]. Obviously, Sil-BIm and Sil-HIm with longer carbon chain showed larger peak area than SilMIm and Sil-EIm. The finger print region of the $-\mathrm{C}-\mathrm{Cl}$ group ranges from 690.0 to $704.0 \mathrm{~cm}^{-1}$, so Sil-EIm-Cl, Sil$\mathrm{BIm}-\mathrm{Cl}$ and Sil-HIm-Cl showed one more conspicuous peak at $694.8 \mathrm{~cm}^{-1}$ than Sil-EIm, Sil-BIm and Sil-HIm. Compared Sil-EIm-Cl and Sil-EIm-NH 2 , the peak of $-\mathrm{C}-\mathrm{Cl}$ was disappeared and the peak at $660.6 \mathrm{~cm}^{-1}$, which was attributed to the $-\mathrm{NH}_{2}$ group proved that $-\mathrm{C}-\mathrm{Cl}$ was replaced as $-\mathrm{C}-\mathrm{NH}_{2}$.

Thermogravimetric analysis can determine the thermo stability of the additional groups on silica with the weight loss and Fig. 3 shows the results from $200{ }^{\circ} \mathrm{C}$ to $600{ }^{\circ} \mathrm{C}$. In Fig. 3 a, with same amount of sorbent, more weight was lost from $12.33 \%$ of Sil-Im to $22.09 \%$ of Sil-HIm because of the increasing of carbon chain on IL group. However, although the carbon chain of Sil-BIm and Sil-HIm were longer than Sil-EIm, the lost weight did not increased much. This is because the hydrophobic property of long carbon chain influenced the synthesis efficiency, especially Sil-HIm. Fig. $3 \mathrm{~b}$ showed that with the same IL group of Sil-EIm, $1.27 \%$ and $4.94 \%$ more weight lost belong to the additional $-\mathrm{NH}_{2}$ and $-\mathrm{Cl}$ groups. Both FT-IR and TGA results indicated the successful immobilization of IL groups on silica.

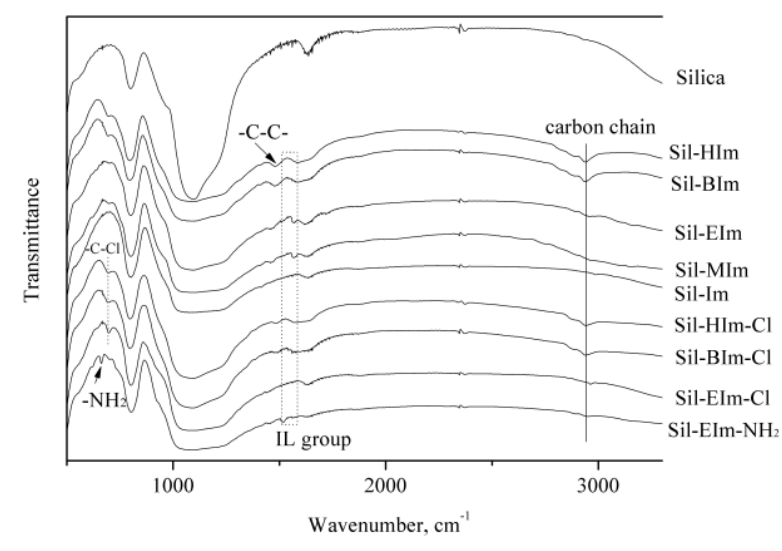

Fig. 2. FT-IR spectra of silica and IL-immobilized sorbents 


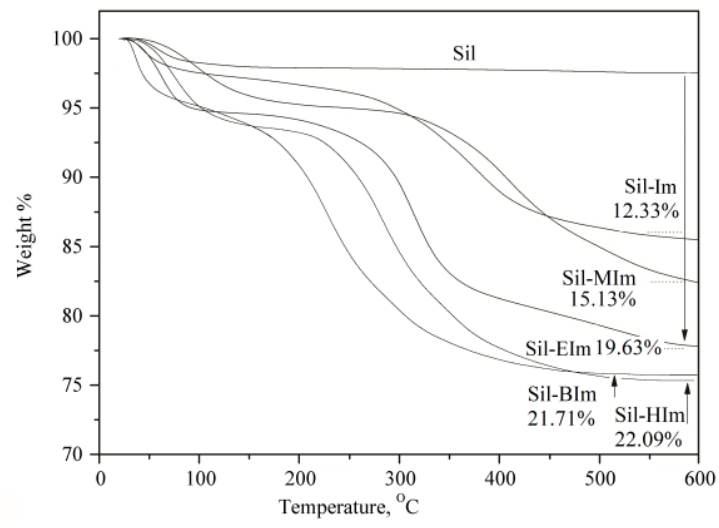

a

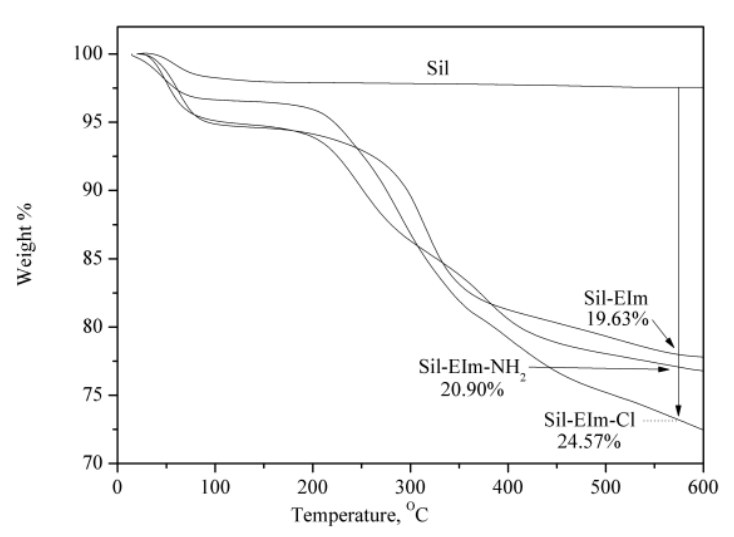

b

Fig. 3. TGA analysis: a - Sil, Sil-Im, Sil-MIm, Sil-EIm, Sil-BIm and Sil-HIm; b - Sil, Sil-EIm, Sil-EIm-NH2, Sil-EIm-Cl

\subsection{Adsorption abilities of different sorbents}

In SPE process, after adsorption equilibrium of two phenols arrived on sorbents, several solvents were used to investigate the strength of interaction by detecting the amount of two phenols in collected solutions. Firstly loading and washing steps were evaluated. Because $o$ cresol and phenol had solubility in water, and the purpose of this research was to remove phenols in water, so water was selected as washing solvent and amounts of removed phenols are shown in Fig. 4 and Fig. 5.

Among Sil-Im, Sil-MIm, Sil-EIm, Sil-BIm and SilHIm, amounts of $o$-cresol and phenol removed by $3.0 \mathrm{~mL}$ of water from Sil-Im and Sil-MIm (less than $0.14 \mu \mathrm{g}$ and $0.024 \mu \mathrm{g}$ respectively) were not much because of hydrogen bonds. With increasing the length of carbon chain on ionic liquid group from Sil-EIm to Sil-HIm, both amounts of $o$ cresol and phenol in washing solvent increased. The phenomenon could be explained with two mechanisms. First, with increasing of carbon chain, the hydrophilic properties of IL groups increased, as well the difference of polarities between IL groups and phenols increased [24]. Second, when the structural volume of IL groups increasing, in an unit surface area the number of effective IL groups which would be bonded phenols was reduced. In this case, water can wash most part of both phenols (more than $0.79 \mu \mathrm{g}$ ) from Sil-BIm and Sil-HIm. In addition, polarity of $o$-cresol was a little lower than phenol, the results showed that $o$-cresol was more trended to Sil-BIm and Sil-HIm although the distinction of adsorption amount had almost no difference.

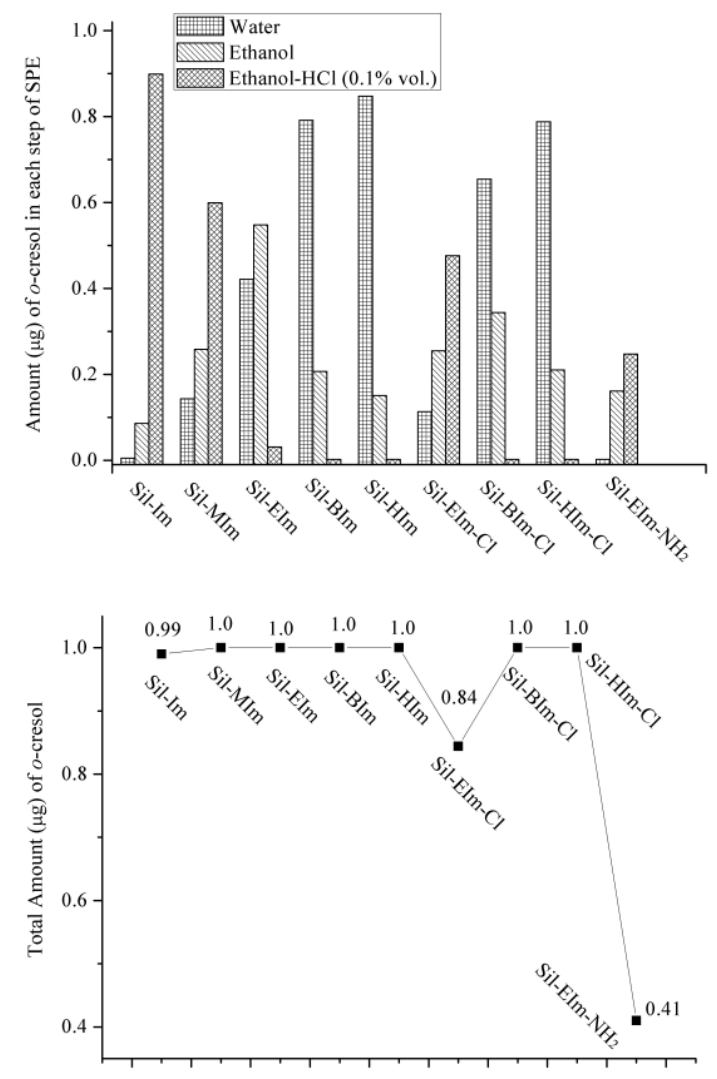

Fig. 4. Detected amount of $o$-cresol from nine sorbents in colleted solutions after washing, elution and cleaning step of SPE
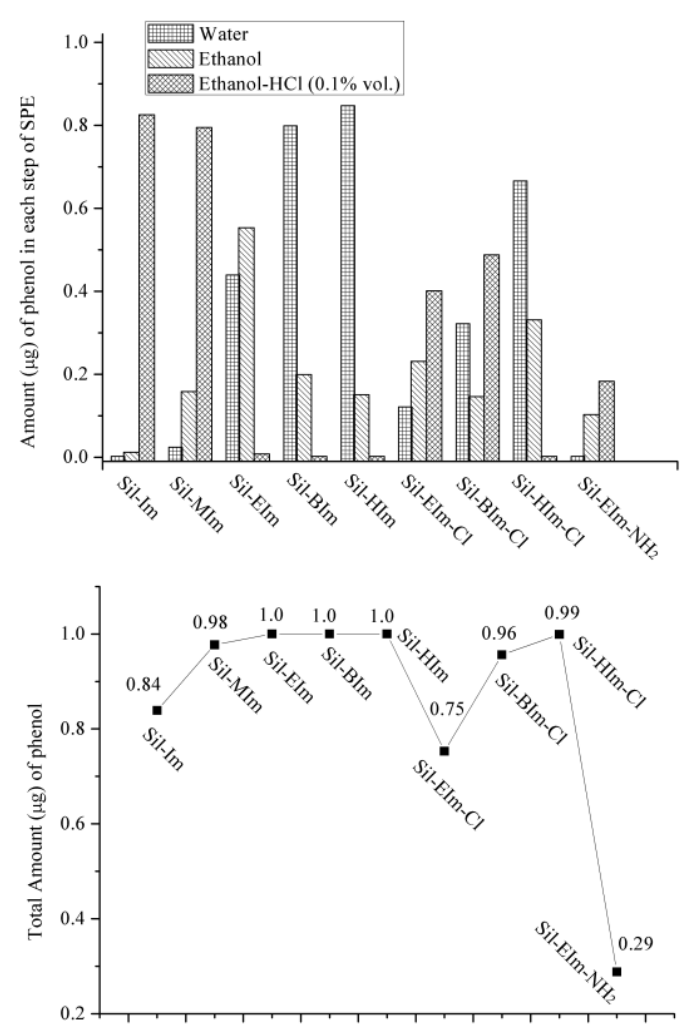

Fig. 5. Detected amount of phenol from nine sorbents in colleted solutions after washing, elution and cleaning step of SPE 
Effect of the interaction between $-\mathrm{Cl}$ and phenols was also shown in the two figures. $-\mathrm{Cl}$ group is an electronwithdrawing group. Because of conjugative effect, -OH groups on $o$-cresol and phenol were electron-donating group [25]. So compare the ILs contained same carbon chain, the $-\mathrm{Cl}$ on IL had more interaction with -OH groups. As the results shown in two figures, washing amount of phenol from Sil-BIm was $0.79 \mu \mathrm{g}$ but from Sil-BIm-Cl the amount decreased to $0.32 \mu \mathrm{g}$. Moreover, washing amount of $o$-cresol from Sil-BIm-Cl was larger than phenol $(0.65 \mu \mathrm{g})$, that because the stereo-effect of methyl group weakened the electron-donating of -OH. For Sil-Im- $\mathrm{NH}_{2}$, no phenols were detected in washing solvent revealed that IL and amino groups can bond with phenols strongly enough.

Elution and cleaning steps were followed. First of all, elution abilities of different organic solvents were tested on Sil-MIm using phenol as target. $3.0 \mathrm{~mL}$ of methanol, ethanol, acetonitrile, hexane and chloroform eluted the SilMIm and $0.16 \mu \mathrm{g}, 0.16 \mu \mathrm{g}, 0.63 \mu \mathrm{g}, 0.013 \mu \mathrm{g}$ and $0.66 \mu \mathrm{g}$ of phenol were detected in eluates respectively. The results showed that the elution ability was lower for hexane, similar for methanol and ethanol, higher for acetonitrile and chloroform. However in consideration of the toxicities of methanol, acetonitrile and chloroform, so ethanol was selected as elution solvent to remove phenols which were adsorbed on materials.

Because the solubility of phenols in ethanol was larger than water, $3.0 \mathrm{~mL}$ of ethanol can elute almost all phenols from Sil-EIm, Sil-BIm, Sil-Him, Sil-BIm-Cl and Sil-HimCl. For Sil-Im, Sil-MIm, Sil-EIm-Cl and Sil-Im-NH${ }_{2}$, the eluted amounts of $o$-cresol were less than $0.26 \mu \mathrm{g}$ and of phenol were less than $0.16 \mu \mathrm{g}$. The results revealed that three groups such as short chain ionic liquid, $-\mathrm{Cl}$ and $-\mathrm{NH}_{2}$ had stronger interaction with phenols. Also in this step SilIm showed more advantage of adsorption on phenol than $o$-cresol as well as than other sorbents.

From the results of commercial sorbents, acid environment was against adsorption, so in final cleaning step ethanol- $\mathrm{HCl}(0.1 \%$ vol. $)$ was used to remove rest of substances from sorbents. The total amounts of two phenols in Fig. 4 and Fig. 5 showed that within $3.0 \mathrm{~mL}$ of cleaning solvent, only $0.41 \mu \mathrm{g}$ of $o$-cresol and $0.29 \mu \mathrm{g}$ of phenol were washed out. More volume $(\geq 15.0 \mathrm{~mL})$ of ethanol- $\mathrm{HCl}$ solution should be needed to elute all phenols from Sil-Im- $\mathrm{NH}_{2}$. In conclusion, IL- $\mathrm{NH}_{2}$ group had the highest interaction with these two phenols.

\subsection{Comparison of IL-immobilized silica and IL- physical adsorbed silica}

In previous research ionic liquid was physically adsorbed on silica, and then the sorbent was used in separation [26]. In this research, Sil/[EMIm]Cl, $\mathrm{Sil} /[\mathrm{BMIm}] \mathrm{Cl}$ and $\mathrm{Sil} /[\mathrm{HMIm}] \mathrm{Cl}$ were packed into three SPE cartridges. $o$-Cresol was used as the target and the SPE process was the same as previous. After loading, $3.0 \mathrm{~mL}$ of water was washed each sorbent and the amount of $o$-cresol in eluates were $0.66 \mu \mathrm{g}, 0.32 \mu \mathrm{g}$ and $0.12 \mu \mathrm{g}$ respectively. When the sorbents were eluted using ethanol, all $o$-cresol were removed.
These three ILs had hydrophilic properties, although the property was decreased with the carbon chain increasing. When they adsorbed on silica only weak hydrogen bonds were formed. In loading step, three sorbents had different behaviors. On Sil/[EMIm]Cl, most of $o$-cresol was bonded with [EMIm]Cl, which had short carbon chain. But the behavior on Sil/[HMIm] Cl was quite different. Because of long carbon chain of $[\mathrm{HMIm}] \mathrm{Cl}$, silica could not adsorb it well but directly bonded $o$-cresol. In washing step water washed out most of ILs from sorbents, $o$-cresol was taken by IL from Sil/[EMIm]Cl but stayed on silica in Sil/[HMIm]Cl. Then hydrogen bonds were destroyed by ethanol so all $o$-cresol were eluted out. The results revealed that IL-immobilized silicas were quite more stable and could be applied for further tests.

\subsection{Effect of different ambient conditions}

According to Fig. 6, under room temperature the adsorption amounts of $o$-cresol increased with time increasing, and there was no obviously increasing after 15 min. The result showed that the adsorption equilibrium was obtained at $15 \mathrm{~min}$. Then the temperature of equilibrium system was increased. As shown in Fig. 7, the adsorption amounts increased with increasing temperature until $35^{\circ} \mathrm{C}$. After that it decreased rapidly under higher temperature. The result means high temperature was unprofitable for adsorption. However, under high temperature the test was repeated for 7 times and the adsorption efficiency of Sil-EIm- $\mathrm{NH}_{2}$ was decreased less than $2 \%$. The good repetition revealed the high stability of ionic liquid-immobilized silica sorbents.

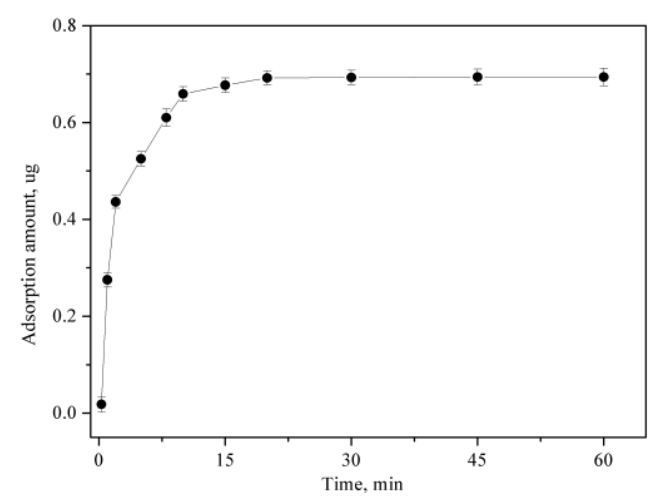

Fig. 6. Effect of adsorption of $o$-cresol with different time on $0.3 \mathrm{~g}$ of Sil-EIm- $\mathrm{NH}_{2}$ under room temperature

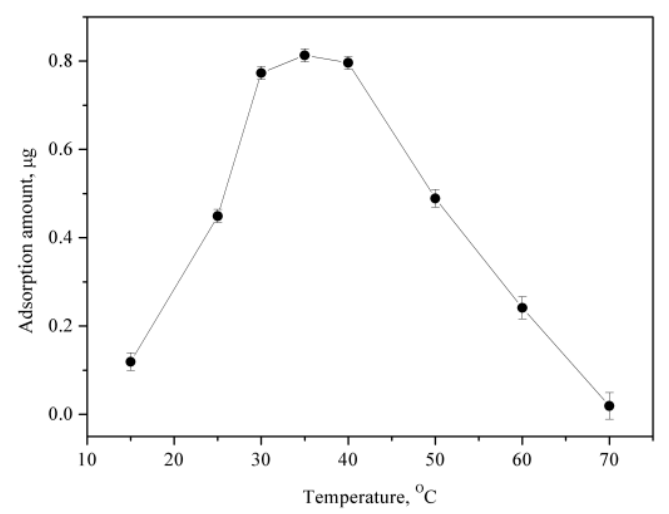

Fig. 7. Effect of adsorption of $o$-cresol under several temperature on $0.3 \mathrm{~g}$ of Sil-EIm- $\mathrm{NH}_{2}$ at $15 \mathrm{~min}$ 


\subsection{Effect of different ions}

In waste water, except phenols there were lots of other substances such as high concentration of ionic salts which may affect the efficiency of sorbents. So several ionic salts were dissolved in water, and larger volume of solutions were used to wash phenol from Sil-Im, Sil-EIm-Cl and SilEIm- $\mathrm{NH}_{2}$. The results are listed in Table 1.

Table 1. Effect of different ions on adsorption of phenol

\begin{tabular}{|c|c|c|c|c|}
\hline Loading & Ion aqueous & \multicolumn{3}{|c|}{ Unadsorbed amount of phenol, $\mu \mathrm{g}$} \\
\cline { 3 - 5 } amount & solutions & Sil-Im & Sil-EIm-Cl & Sil-EIm-NH \\
\hline \multirow{5}{*}{10 g } \\
\hline \multirow{5}{*}{} & $\mathrm{H}_{2} \mathrm{O}$ (Ref) & 0.01 & 1.21 & 0.00 \\
\cline { 2 - 5 } & $\mathrm{NaCl}$ & 0.014 & 2.42 & 0.010 \\
\cline { 2 - 5 } & $\mathrm{KCl}$ & 0.015 & 2.44 & 0.010 \\
\cline { 2 - 5 } & $\mathrm{MgCl}_{2}$ & 0.24 & 3.22 & 0.021 \\
\cline { 2 - 5 } & $\mathrm{AlCl}_{3}$ & 0.31 & 3.38 & 0.023 \\
\cline { 2 - 5 } & $\mathrm{CaCl}_{2}$ & 0.38 & 3.71 & 0.031 \\
\cline { 2 - 5 } & $\mathrm{FeCl}_{3}$ & 0.96 & 5.13 & 1.22 \\
\cline { 2 - 5 } & $\mathrm{Na}_{2} \mathrm{CO}_{3}$ & 0.020 & 2.45 & 1.33 \\
\cline { 2 - 5 } & $\mathrm{NaHCO}_{3}$ & 0.010 & 1.22 & 0.52 \\
\cline { 2 - 5 } & $\mathrm{Na}_{2} \mathrm{HPO}_{4}$ & 0.010 & 1.24 & 0.57 \\
\cline { 2 - 5 } & $\mathrm{NaH}_{2} \mathrm{PO}_{4}$ & 0.52 & 4.11 & 6.98 \\
\hline
\end{tabular}

Firstly, salts with different cation ions were investigated. Compared amount of phenol with pure water,
$\mathrm{NaCl}$ and $\mathrm{KCl}$ solution washed same amount from SilMIm and Sil-EIm-NH $\mathrm{NH}_{2}$ For $\mathrm{MgCl}_{2}, \mathrm{AlCl}_{3}$ and $\mathrm{CaCl}_{2}$, the aqueous solutions were quite weak acid, so washed amounts were a little more than pure water. For aqueous solution of $\mathrm{FeCl}_{3}$ the acidity was much higher than other chloride salts [27], so the washing ability was stronger according to the results in Table 1. Additionally, ionic salts which included $\mathrm{Cl}$ - anion effect the adsorption ability of Sil-EIm- $\mathrm{Cl}$ because the $-\mathrm{Cl}$ anions in water blocked the interaction between the sorbent and phenol. Secondly, sodium salts with different anions were tested. When $\mathrm{NaHCO}_{3}$ and $\mathrm{Na}_{2} \mathrm{HPO}_{4}$ were used, the $\mathrm{pH}$ of aqueous solutions was no changed too much, so washing amounts with these two salt solutions were not difference from pure water. $\mathrm{Na}_{2} \mathrm{CO}_{3}$ was a base so there was large concentration of -OH group in aqueous solution, and they had competition adsorption with phenol on sorbents. Moreover, the aqueous solution of $\mathrm{NaH}_{2} \mathrm{PO}_{4}$ was an acid it can wash out the highest amount of phenol from sorbents.

\subsection{Comparative evaluation on the analytical performance}

Table 2 provides a comparison of the proposed ILbased silica with other commonly methods for the determination of phenols in environmental water samples.

Table 2. Comparison of the analytical performance of the proposed ionic liquid material with literature reported work

\begin{tabular}{|c|c|c|c|c|c|c|c|c|}
\hline Sorbent & Analyte & Sample & $\begin{array}{l}\text { Detection } \\
\text { method }\end{array}$ & $\begin{array}{c}\text { Spiked } \\
\text { concentration, } \\
\mu \mathrm{g} / \mathrm{L}\end{array}$ & $\begin{array}{c}\text { Recovery, } \\
\%\end{array}$ & $\begin{array}{l}\text { Intra-day } \\
\text { RSD, \% }\end{array}$ & $\begin{array}{l}\text { Inter-day } \\
\text { RSD, \% }\end{array}$ & Ref. \\
\hline $\begin{array}{l}\text { IL-based silica } \\
\left(\mathrm{SiO}_{2}-\mathrm{ClPrNTf}_{2}\right)\end{array}$ & $\begin{array}{l}\text { 1-NAA, 4- } \\
\mathrm{CA}, 4-\mathrm{CP}, 4- \\
\mathrm{MP}, 4-\mathrm{NP}, \\
\text { isatin and } \\
\text { phenazone }\end{array}$ & $\begin{array}{l}\text { Drinking, } \\
\text { ground, } \\
\text { lake, sea and } \\
\text { waste water }\end{array}$ & $\begin{array}{l}\text { Liuqid-solid } \\
\text { adsorption }\end{array}$ & $25.0-75.0$ & $82.1-99.5$ & Average 4.9 & & 28 \\
\hline $\begin{array}{l}\text { IL-based } \\
\text { surfactants } \\
\left(\mathrm{C}_{12} \mathrm{C}_{12} \mathrm{Im}-\mathrm{Br} \text {, et }\right. \\
\text { al.) }\end{array}$ & $\begin{array}{l}\text { Phenol, 2-CP, } \\
\text { 2,4-DMP, 4-t- } \\
\text { BP, 4-OP, 4- } \\
\text { CuP, BPA, 4- } \\
\text { NP }\end{array}$ & $\begin{array}{l}\text { Waste and } \\
\text { tap water }\end{array}$ & SPME & 15.0 and 50.0 & $85.4-123.0$ & $1.6-13.0$ & $5.8-17.0$ & 29 \\
\hline $\begin{array}{l}\text { IL organic- } \\
\text { inorganic hybrid } \\
\text { nanomaterial } \\
(\mathrm{LDH} / \mathrm{DABCO})\end{array}$ & $\begin{array}{l}\text { Phenol, 4-CP, } \\
\text { 2,4-DP, 2,6- } \\
\text { DP, 2,4,6-TP, } \\
\text { 3-AP, 4-AP, } \\
\text { 3-NP, 4-NP }\end{array}$ & $\begin{array}{l}\text { Chichih } \\
\text { river, } \\
\text { Polsangi } \\
\text { bridge }\end{array}$ & SPME & 0.01 to 500.0 & - & $0.02-5.3$ & - & 30 \\
\hline $\begin{array}{l}\text { IL-based silica } \\
\left(\text { SilprMimPF }_{6}\right)\end{array}$ & $\begin{array}{l}\text { Phenol, 2,4- } \\
\text { DP, 2,4,6-TP, } \\
\text { PCP }\end{array}$ & $\begin{array}{l}\text { Tap and } \\
\text { river water }\end{array}$ & SPE & $10.0-100.0$ & $47.8-101.4$ & - & $3.7-8.8$ & 31 \\
\hline $\begin{array}{l}\text { Silica-titania } \\
\text { oxide sol-gel } \\
\text { based IL (Si- } \\
\text { Ti@CN/IL) }\end{array}$ & $\begin{array}{l}\text { 2-CP, 3-CP, } \\
\text { 2,4-DP, 2,4,6- } \\
\text { TP, 2,3,4,6- } \\
\text { TTP, PCP }\end{array}$ & $\begin{array}{l}\text { Tap and lake } \\
\text { water, } \\
\text { leachate } \\
\text { from landfill } \\
\text { site }\end{array}$ & SPE & $\begin{array}{l}5.0 \text { and } \\
1000.0\end{array}$ & $73.4-105.5$ & $2.3-4.7$ & $1.6-4.3$ & 32 \\
\hline $\begin{array}{l}\text { Nine IL-silicas } \\
\text { (Sil-EIm-NH }{ }_{2} \text {, et } \\
\text { al.) }\end{array}$ & $\begin{array}{l}\text { Phenol, } o- \\
\text { cresol }\end{array}$ & $\begin{array}{l}\text { Seven water } \\
\text { and soil } \\
\text { samples }\end{array}$ & SPE & $0.0-200.0$ & $86.0-110.0$ & $3.8-5.9$ & $4.1-6.2$ & $\begin{array}{l}\text { This } \\
\text { work }\end{array}$ \\
\hline \multicolumn{9}{|c|}{$\begin{array}{l}\text { 1-NAA: 1-naphthylacetic acid; 4-CA: 4-chloroaniline; 4-CP: 4-Chlorophenol; 4-MP: 4-methoxyphenol; 4-NP: 4-nitrophenol; 2-CP: 2- } \\
\text { Chlorophenol; 3-CP: 3-Chlorophenol; 2,4-DMP: 2,4-dimethylphenol; 4-t-BP: 4-tert-Butylphenol; 4-OP: 4-octylphenol; 4-CuP: 4- } \\
\text { cumylphenol; BPA: bisphenol A; 4-NP: 4-nonylphenol; 4-CP: 4-Chlorophenol; 2,4-DP: 2,4-Dichlorophenol; 2,6-DP: 2,6- } \\
\text { Dichlorophenol; 2,4,6-TP: 2,4,6-Trichlorophenol; 2,3,4,6-TTP: 2,3,4,6-tetrachlorophenol; 3-AP: 3-Aminophenol; 4-AP: 4-Aminophenol; } \\
\text { 3-NP: 3-Nitrophenol; 4-NP: 4-Nitrophenol; PCP: Pentachlorophenol; SPME: solid phase microextraction, SPE: solid-phase extraction }\end{array}$} \\
\hline
\end{tabular}


Normal liquid-solid adsorption method with $\mathrm{SiO}_{2}-\mathrm{ClPrNTf}_{2}$ material achieved recoveries of $82.1-99.5 \%$ and average RSD of $4.9 \%$ for seven phenols in five water samples [28]. Solid-phase microextraction can detect small amount of phenols in water samples. Trujillo-Rodríguez et al. used the method to extract eight phenols with $\mathrm{C}_{12} \mathrm{C}_{12} \mathrm{Im}-\mathrm{Br}$ material from two water samples although the RSD was higher than other researches [29]. Abolghasemi et al. used LDH/DABCO nanomaterial to extract nine phenols from two water samples with RSD of $0.02-5.3 \%$ [30]. Solid-phase extraction was the most widely used method. Su et al. used SilprMimPF 6 and Bakhshaei et al. used Si-Ti@CN/IL to extract several phenols from water and leachate with similar recoveries, and RSDs of Si-Ti@CN/IL were higher than SilprMimPF 6 [31, 32]. Thus, RSDs of all researches in Table 2 were slightly different, the effects of necessary factors-different inorganic salts-were investigated in this work.

\subsection{Analysis of phenols in real water and soil samples}

Finally the proposed method was applied to determination of two phenols in real water and soil samples. By HPLC detection, the amount of phenols in
$10.0 \mathrm{~mL}$ of real samples were lower than $2.0 \mu \mathrm{g}$. In this case, $0.0-2.0 \mu \mathrm{g}$ amounts of phenols were added to the samples and analyzed for recovery experiments. Also according to previous results, Sil-Em- $\mathrm{NH}_{2}$ which exhibited higher adsorption ability and interaction strength was selected as the optimized sorbent. The results in Table 3 showed that except water from Yangtze River, a lake and plant effluent, phenols were not detected in other samples. The recoveries are from $82.00 \%$ to $110.00 \%$. Moreover, the intra-day and inter-day relative standard deviation (RSD) which were less than $6.14 \%$ showed the high precision of the method.

\section{CONCLUSIONS}

In this study, nine ionic liquid immobilized silicas were prepared and applied as sorbents in SPE to adsorb two phenols in real water and soil samples. FT-IR and TGA results revealed that the IL groups were successfully immobilized. The performance of IL-immobilized silicas was compared with IL-physically adsorbed on silica, and Sil-ILs were quite more stable. The adsorption abilities of all sorbents were evaluated by SPE with $3.0 \mathrm{~mL}$ of water, ethanol and ethanol- $\mathrm{HCl}(0.1 \%$ vol.) as washing, elution and cleaning solvent, respectively.

Table 3. Determine of phenol and $o$-cresol in four water samples and three soil samples by SPE with Sil-EIm- $\mathrm{NH}_{2}$ as sorbent

\begin{tabular}{|c|c|c|c|c|c|c|}
\hline Sample & Analyte & Added, $\mu \mathrm{g}$ & Founded, $\mu \mathrm{g}$ & Recovery, \% & $\begin{array}{c}\text { Intra-day RSD, } \\
\%, \mathrm{n}=3\end{array}$ & $\begin{array}{c}\text { Inter-day RSD, } \\
\%, \mathrm{n}=3\end{array}$ \\
\hline Yangtze River water & \multirow{7}{*}{ Phenol } & \multirow{7}{*}{$\begin{array}{l}0.00 \\
0.50 \\
1.00 \\
1.50 \\
2.00\end{array}$} & $\begin{array}{c}0.03 \pm 0.001 \\
0.51 \pm 0.09 \\
1.05 \pm 0.15 \\
1.49 \pm 0.19 \\
2.01 \pm 0.23\end{array}$ & $\begin{array}{c}- \\
96.00 \\
102.00 \\
97.33 \\
99.00 \\
\end{array}$ & $\begin{array}{l}3.87 \\
4.35 \\
4.58 \\
4.44 \\
4.87 \\
\end{array}$ & $\begin{array}{l}4.12 \\
4.56 \\
4.63 \\
4.86 \\
5.03 \\
\end{array}$ \\
\hline Lake water & & & $\begin{array}{c}0.00 \\
0.49 \pm 0.05 \\
0.98 \pm 0.12 \\
1.43 \pm 0.15 \\
1.87 \pm 0.16\end{array}$ & $\begin{array}{c}- \\
98.00 \\
98.00 \\
95.33 \\
93.50\end{array}$ & $\begin{array}{l}- \\
4.68 \\
4.21 \\
4.45 \\
5.01\end{array}$ & $\begin{array}{c}- \\
4.89 \\
4.97 \\
4.68 \\
5.58 \\
\end{array}$ \\
\hline Well water & & & $\begin{array}{c}0.00 \\
0.46 \pm 0.04 \\
0.89 \pm 0.13 \\
1.53 \pm 0.13 \\
1.88 \pm 0.12\end{array}$ & $\begin{array}{c}- \\
92.00 \\
89.00 \\
102.00 \\
94.00 \\
\end{array}$ & $\begin{array}{l}- \\
4.38 \\
4.25 \\
4.44 \\
4.79 \\
\end{array}$ & $\begin{array}{l}- \\
4.38 \\
4.99 \\
4.68 \\
5.02 \\
\end{array}$ \\
\hline Plant effluent & & & $\begin{array}{l}0.43 \pm 0.02 \\
0.98 \pm 0.11 \\
1.32 \pm 0.23 \\
1.83 \pm 0.34 \\
2.40 \pm 0.12\end{array}$ & $\begin{array}{c}- \\
110.00 \\
89.00 \\
93.33 \\
98.50\end{array}$ & $\begin{array}{l}5.01 \\
5.24 \\
5.12 \\
5.47 \\
5.43\end{array}$ & $\begin{array}{l}5.53 \\
5.50 \\
5.21 \\
5.55 \\
5.64\end{array}$ \\
\hline \#1 soil sample & & & $\begin{array}{c}0.00 \\
0.45 \pm 0.02 \\
0.99 \pm 0.13 \\
1.47 \pm 0.21 \\
1.80 \pm 0.15 \\
\end{array}$ & $\begin{array}{c}- \\
90.00 \\
99.00 \\
98.00 \\
90.00 \\
\end{array}$ & $\begin{array}{c}- \\
5.36 \\
5.12 \\
5.66 \\
5.80 \\
\end{array}$ & $\begin{array}{l}- \\
5.62 \\
5.38 \\
5.63 \\
5.92 \\
\end{array}$ \\
\hline \#2 soil sample & & & $\begin{array}{c}0.00 \\
0.43 \pm 0.05 \\
0.94 \pm 0.15 \\
1.44 \pm 0.14 \\
1.95 \pm 0.28\end{array}$ & $\begin{array}{c}- \\
86.00 \\
94.00 \\
96.00 \\
97.50 \\
\end{array}$ & $\begin{array}{c}- \\
5.38 \\
5.33 \\
5.78 \\
5.91 \\
\end{array}$ & $\begin{array}{l}- \\
5.77 \\
5.87 \\
6.00 \\
6.21 \\
\end{array}$ \\
\hline \#3 soil sample & & & $\begin{array}{c}0.00 \\
0.41 \pm 0.03 \\
0.91 \pm 0.12 \\
1.51 \pm 0.17 \\
1.99 \pm 0.27 \\
\end{array}$ & $\begin{array}{c}- \\
82.00 \\
91.00 \\
101.67 \\
99.50 \\
\end{array}$ & $\begin{array}{c}- \\
5.73 \\
5.23 \\
5.88 \\
5.76 \\
\end{array}$ & $\begin{array}{c}- \\
5.91 \\
5.55 \\
6.01 \\
6.02 \\
\end{array}$ \\
\hline
\end{tabular}


Table 3. Continuation

\begin{tabular}{|c|c|c|c|c|c|c|}
\hline Sample & Analyte & Added, $\mu \mathrm{g}$ & Founded, $\mu \mathrm{g}$ & Recovery, \% & $\begin{array}{c}\text { Intra-day RSD, } \\
\%, \mathrm{n}=3\end{array}$ & $\begin{array}{c}\text { Inter-day RSD, } \\
\%, \mathrm{n}=3\end{array}$ \\
\hline Yangtze River water & \multirow{7}{*}{$o$-Cresol } & \multirow{7}{*}{$\begin{array}{l}0.00 \\
0.50 \\
1.00 \\
1.50 \\
2.00\end{array}$} & $\begin{array}{l}0.12 \pm 0.02 \\
0.63 \pm 0.09 \\
1.11 \pm 0.08 \\
1.53 \pm 0.21 \\
2.08 \pm 0.35\end{array}$ & $\begin{array}{c}- \\
102.00 \\
99.00 \\
94.00 \\
98.00\end{array}$ & $\begin{array}{l}5.03 \\
5.02 \\
5.11 \\
5.32 \\
5.32 \\
\end{array}$ & $\begin{array}{l}5.17 \\
5.41 \\
5.36 \\
5.78 \\
5.69\end{array}$ \\
\hline Lake water & & & $\begin{array}{c}0.06 \pm 0.002 \\
0.56 \pm 0.05 \\
1.07 \pm 0.12 \\
1.45 \pm 0.15 \\
1.97 \pm 0.16 \\
\end{array}$ & $\begin{array}{c}- \\
100.00 \\
101.00 \\
92.67 \\
95.50 \\
\end{array}$ & $\begin{array}{l}4.88 \\
5.36 \\
5.59 \\
5.45 \\
5.88 \\
\end{array}$ & $\begin{array}{l}5.02 \\
5.46 \\
5.66 \\
5.89 \\
5.93 \\
\end{array}$ \\
\hline Well water & & & $\begin{array}{c}0.00 \\
0.44 \pm 0.03 \\
0.86 \pm 0.14 \\
1.49 \pm 0.12 \\
1.85 \pm 0.13\end{array}$ & $\begin{array}{c}- \\
88.00 \\
86.00 \\
99.33 \\
92.50 \\
\end{array}$ & $\begin{array}{l}- \\
4.18 \\
4.28 \\
4.24 \\
4.81 \\
\end{array}$ & $\begin{array}{l}- \\
4.36 \\
4.69 \\
4.64 \\
4.82\end{array}$ \\
\hline Plant effluent & & & $\begin{array}{l}0.58 \pm 0.12 \\
1.10 \pm 0.21 \\
1.61 \pm 0.22 \\
2.01 \pm 0.43 \\
2.43 \pm 0.20\end{array}$ & $\begin{array}{c}- \\
104.00 \\
103.00 \\
95.33 \\
92.50\end{array}$ & $\begin{array}{l}5.23 \\
5.46 \\
5.34 \\
5.69 \\
5.65\end{array}$ & $\begin{array}{l}5.75 \\
5.73 \\
5.43 \\
5.77 \\
5.86\end{array}$ \\
\hline \#1 soil sample & & & $\begin{array}{c}0.00 \\
0.46 \pm 0.03 \\
0.89 \pm 0.14 \\
1.49 \pm 0.20 \\
1.78 \pm 0.14 \\
\end{array}$ & $\begin{array}{c}- \\
92.00 \\
89.00 \\
99.33 \\
89.00 \\
\end{array}$ & $\begin{array}{l}- \\
5.16 \\
5.14 \\
5.46 \\
5.82 \\
\end{array}$ & $\begin{array}{l}- \\
5.42 \\
5.40 \\
5.43 \\
5.95 \\
\end{array}$ \\
\hline \#2 soil sample & & & $\begin{array}{c}0.00 \\
0.45 \pm 0.01 \\
0.99 \pm 0.10 \\
1.47 \pm 0.09 \\
2.00 \pm 0.23\end{array}$ & $\begin{array}{c}- \\
90.00 \\
99.00 \\
98.00 \\
100.00 \\
\end{array}$ & $\begin{array}{c}- \\
5.33 \\
5.27 \\
5.83 \\
5.86 \\
\end{array}$ & $\begin{array}{c}- \\
5.83 \\
5.82 \\
5.95 \\
6.11 \\
\end{array}$ \\
\hline \#3 soil sample & & & $\begin{array}{c}0.00 \\
0.46 \pm 0.02 \\
0.95 \pm 0.11 \\
1.50 \pm 0.16 \\
1.95 \pm 0.23\end{array}$ & $\begin{array}{c}- \\
92.00 \\
95.00 \\
100.00 \\
97.50 \\
\end{array}$ & $\begin{array}{c}- \\
5.62 \\
5.34 \\
5.76 \\
5.87 \\
\end{array}$ & $\begin{array}{l}- \\
5.78 \\
5.42 \\
5.98 \\
6.14 \\
\end{array}$ \\
\hline
\end{tabular}

Sil-Im- $\mathrm{NH}_{2}$ showed the highest adsorption ability and under $35{ }^{\circ} \mathrm{C}$ for $15 \mathrm{~min}$ the largest amount of two phenols was adsorbed and was stable with 7 times repetition. Also the effect of different ions on adsorption efficiency was evaluated, as well as the result of $\mathrm{HCl}$ in ethanol, the acidity of $\mathrm{FeCl}_{3}$ and $\mathrm{NaH}_{2} \mathrm{PO}_{4}$ solution was reduced the performance of sorbents. Finally, two phenols in water and soil samples were detected using SPE with a $0.0-2.0 \mu \mathrm{g}$ spiked amount. From the result of recoveries $86.0-110.0 \%$ and RSD less than $6.14 \%$, Sil-EIm- $\mathrm{NH}_{2}$ was found as a high efficiency and better selectivity sorbent to separate two phenols from water sample. Also this type of sorbents has a potential for separation of phenol samples with complicated matrices. Therefore, ionic liquid-immobilized silica with SPE can substantially separate phenols from environmental samples and it has a great application value in the detection of a wide range pollutants.

\section{Acknowledgement}

This work was supported by the National Natural Science Foundation of China (No. 51503020, 51472034) and by the program of China Scholarships Council (No.201808420038).

\section{REFERENCES}

1. Mirzaei, M., Amirtaimoury, N. Temperature-induced Aggregation Ionic Liquid Dispersive Liquid-Liquid Microextraction Method for Separation Trace Amount of Cobalt Ion Journal of Analytical Chemistry 69 2014: pp. 503-508 https://doi.org/10.1134/S1061934814060112

2. Ng, Y.S., Jayakumar, N.S., Hashim, M.A. Behavior of Hydrophobic Ionic Liquids as Liquid Membranes on Phenol Removal: Experimental Study and Optimization Desalination 278 2011: pp. 250-258. https://doi.org/10.1016/j.desal.2011.05.047

3. Busca, G., Berardinelli, S., Resini, C., Arrighi, L. Technologies for the Removal of Phenol from Fluid Streams: A Short Review of Recent Developments Journal of Hazardous Materials $160(2-3)$ 2008: pp. 265-288. https://doi.org/10.1016/j.jhazmat.2008.03.045

4. Kallel, M., Belaid, C., Mechichi, T., Ksibi, M., Elleuch, B. Removal of Organic Load and Phenolic Compounds from Olive Mill Wastewater by Fenton Oxidation with ZeroValent Iron Chemical Engineering Journal $150(2-3)$ 2009: pp. $391-395$. https://doi.org/10.1016/j.cej.2009.01.017

5. Chedeville, O., Debacq, M., Porte, C. Removal of Phenolic Compounds Present in Olive Mill Wastewaters by Ozonation 
Desalination 249 (2) 2009: pp. 865-869.

https://doi.org/10.1016/j.desal.2009.04.014

6. Parida, K.M., Pradhan, A.C. Removal of Phenolic Compounds from Aqueous Solutions by Adsorption onto Manganese Nodule Leached Residue Journal of Hazardous Materials $173(1-3)$ 2010: pp. 758-764. https://doi.org/10.1016/j.jhazmat.2009.09.003

7. Abdelwahab, O., Amin, N.K., El-Ashtoukhy, E. Electrochemical Removal of Phenol from Oil Refinery Wastewater Journal of Hazardous Materials $163(2-3)$ 2009: pp. $711-716$.

https://doi.org/10.1016/j.jhazmat.2008.07.016

8. Yavuz, Y., Koparal, A.S., Ogutveren, U.B. Treatment of Petroleum Refinery Wastewater by Electrochemical Methods Desalination $258(1-3)$ 2010: pp. 201-205. https://doi.org/10.1016/j.desal.2010.03.013

9. Sereshti, H., $\quad$ Eskandarpour, N., $\quad$ Samadi, S., Aliakbarzadeh, Gh. Investigation on Dracaena Sanderiana Phytoremediation Ability for $\mathrm{Hg}$ and $\mathrm{Cd}$ Using Multivariate Optimized Task Specific Ionic Liquid-Based Dispersive Liquid-Liquid Microextraction International Journal of Environmental Research 8 (4) 2014: pp. 1075-1084. https://doi.org/10.22059/IJER.2014.801

10. Zhang, D.H., Bai, S., Ren, M.Y., Sun, Y. Optimization of Lipase-Catalyzed Enantioselective Esterification of $( \pm)$ Menthol in Ionic Liquid Food Chemistry 109 (1) 2008: pp. $72-80$. https://doi.org/10.1016/j.foodchem.2007.12.020

11. Pandey, S. Analytical Applications of Room-Temperature Ionic Liquids: A Review of Recent Efforts Analytica Chimica Acta 556 (1) 2006: pp. 38-45. https://doi.org/10.1016/j.aca.2005.06.038

12. Cole, A.C., Jensen, J.L., Ntai, I., Tran, K.L., Weaver, K.J., Forbes, D.C., Davis, J.H. Novel Bronsted Acidic Ionic Liquids and Their Use as Dual Solvent-Catalysts Journal of the American Chemical Society 124 2002: pp. 5962-5963. https://doi.org/10.1021/ja026290w

13. Liu, J., Jiang, G., Chi, Y., Cai, Y., Zhou, Q., Hu, J.T. Use of Ionic Liquids for Liquid-Phase Microextraction of Polycyclic Aromatic Hydrocarbons Analytical Chemistry 75 2003: pp. 5870-5876. https://doi.org/10.1021/ac034506m

14. Bi, W., Tian, M., Row, K.H. Solid-Phase Extraction of Matrine and Oxymatrine from Sophora Flavescens Ait Using Amino-Imidazolium Polymer Journal of Separation Science 33 (12) 2010: pp. 1739-1745. https://doi.org/10.1002/jssc.200900835

15. Khan, S., Soylak, M., Kazi, T.G. Room Temperature Ionic Liquid-Based Dispersive Liquid Phase Microextraction for the Separation/Preconcentration of Trace $\mathrm{Cd} 2+$ as 1-(2Pyridylazo)-2-naphthol (PAN) Complex from Environmental and Biological Samples and Determined by FAAS Biological Trace Element Research 156 2013: pp. 49-55. https://doi.org/10.1007/s12011-013-9853-y

16. Fischer, L., Falta, T., Koellensperger, G., Stojanovic, A., Kogelnig, D., Galanski, M., Krachler, R., Keppler, B.K., Hann, S. Ionic liquids for Extraction of Metals and Metal Containing Compounds from Communal and Industrial Waste Water Water Research 45 2011: pp. 4601-4614. https://doi.org/10.1016/j.watres.2011.06.011

17. Balasubramanian, A., Venkatesan, S. Removal of Phenolic Compounds from Aqueous Solutions by Emulsion Liquid Membrane Containing Ionic Liquid $[\mathrm{BMIM}]^{+}[\mathrm{PF} 6]^{-}$in Tributyl Phosphate Desalination 289 2012: pp. 27-34. https://doi.org/10.1016/j.desal.2011.12.027
18. Raoov, M., Mohamad, S., Abas, M.R. Removal of 2,4Dichlorophenol using Cyclodextrin-Ionic Liquid polymer as a Macroporous Material: Characterization, Adsorption isotherm, Kinetic Study, Thermodynamics Journal of Hazardous Materials 263 2013: pp. 501-516. https://doi.org/10.1016/j.jhazmat.2013.10.003

19. Altšmíd, J., Syrový, T., Syrová, L., $\quad$ Kuberský, P., Hamáček, A., Zmeškal, O., Nešpůrek, S. Ionic Liquid Based Polymer Electrolytes for $\mathrm{NO}_{2}$ Electrochemical Sensors Materials Science (Medžiagotyra) 21 (3) 2015: pp. $415-418$. http://dx.doi.org/10.5755/j01.ms.21.3.7371

20. Li, Z., Jia, J., Wang, M., Zhang, H., Yan, H., Qiao, F. Bifunctionalized Ordered Mesoporous Organosilica Synthesized in Deep Eutectic Solvent for Extraction of Triazine Herbicides from Watermelon Journal of Chromatography A 1529 2017: pp. 50-56. https://doi.org/10.1016/j.chroma.2017.10.074

21. Wang, L., Yan, H., Yang, C., Li, Z., Qiao, F. Synthesis of Mimic Molecularly Imprinted Ordered Mesoporous Silica Adsorbent by Thermally Reversible Semicovalent Approach for Pipette-Tip Solid-Phase Extraction-Liquid Chromatography Fluorescence Determination of Estradiol in Milk Journal of Chromatography A 1456 2016: pp. $58-67$. https://doi.org/10.1016/j.chroma.2016.06.010

22. Tian, M., Bi, W., Row, K.H. Molecular Imprinting in Ionic Liquid-Modified Porous Polymer for Recognitive Separation of Three Tanshinones from Salvia Miltiorrhiza Bunge Analytical and Bioanalytical Chemistry 399 2011: pp. $2495-2502$. https://doi.org/10.1007/s00216-010-4641-4

23. Ramanathan, T., Fisher, F.T., Ruoff, R.S., Brinson, L.C. Amino-Functionalized Carbon Nanotubes for Binding to Polymers and Biological Systems Chemistry of Materials 17 2005: pp. 1290-1295. https://doi.org/10.1021/cm048357f

24. Ng, Y.S., Jayakumar, N.S., Hashim, M.A. Behavior of Hydrophobic Ionic Liquids as Liquid Membranes on Phenol Removal: Experimental Study and Optimization Desalination 278 2011: pp. 250-258. https://doi.org/10.1016/j.desal.2011.05.047

25. Pogorelyi, V.K., Divnich, T.F. Proton-donating Capacity of Phenol and Its Thio and Seleno Analogs in A Hydrogen Bond with Electron Donors Theoretical and Experimental Chemistry 12 1976: pp. 648-652. https://doi.org/10.1007/BF01001710

26. Mahmoud, M.E., Albishri, H.M. Nano-silica Sorbents Immobilized Hydrophobic Ionic Liquids for Enhanced Adsorptive Extraction of Cadmium from Acidic Aqueous Solutions Desalination and Water Treatment 49 2012: pp. $348-358$. https://doi.org/10.1080/19443994.2012.719464

27. Brady, G.W., Robin, M.B., Varimbi, J. The Structure of Ferric Chloride in Neutral and Acid Solutions Inorganic Chemistry 3 1964: pp. 1168-1173. https://doi.org/10.1021/ic50018a023

28. Marwani, H.M., Bakhsh, E.M. Selective Adsorption of 4Chlorophenol Based on Silica-Ionic Liquid Composite Developed by Sol-Gel Process Chemical Engineering Journal 326 2017: pp. 794-802. https://doi.org/10.1016/j.cej.2017.06.030

29. Trujillo-Rodríguez, M.J., Pino, V., Anderson, J.L., Ayala, J.H., Afonso, A.M. Double Salts of Ionic-LiquidBased Surfactants in Microextraction: Application of Their 
Mixed Hemimicelles as Novel Sorbents in MagneticAssisted Micro-Dispersive Solid-Phase Extraction for the Determination of Phenols Analytical and Bioanalytical Chemistry 407 2015: pp. 8753-8764.

https://doi.org/10.1007/s00216-015-9034-2

30. Abolghasemi, M.M., Yousefi, V., Piryaei, M. Doublecharged Ionic Liquid-functionalized Layered Double Hydroxide Nanomaterial as A New Fiber Coating for SolidPhase Microextraction of Phenols Microchimica Acta 182 2015: pp. $2155-2164$.

https://doi.org/10.1007/s00604-015-1553-1
31. Su, P., Wang, R., Yu, Y., Yang, Y. Microwave-Assisted Synthesis of Ionic Liquid modified Silica as A Sorbent for the Solid-Phase Extraction of Phenolic Compounds from Water Analytical Methods 6 2014: pp. 704-709. https://doi.org/10.1039/C3AY41771A

32. Bakhshaei, S., Kamboh, M.A., Mohamad, S., Zain, S.M., Ma'amor, A. A Novel Cyano Functionalized Silica-Titania Oxide Sol-Gel Based Ionic Liquid for the Extraction of Hazardous Chlorophenols from Aqueous Environments RSC Advances 6 2016: pp. 49358-49369.

https://doi.org/10.1039/C6RA08337D 